\title{
GOUT AND \\ CEREBRAL PALSY IN A THREE-YEAR-OLD BOY \\ BY
}

\author{
IAN D. RILEY \\ From Stobhill Hospital, Glasgow
}

(RECEIVED FOR PUBLICATION JULY 6, 1959)

Gout is very uncommon in children, and its appearance in a patient with cerebral palsy does not appear to have been recorded before.

\section{Case Report}

A.W. was born on January 20, 1951, at full term after a normal delivery and weighed $7 \mathrm{lb} .6 \mathrm{oz}$. He was adopted after medical examination aged 1 week. He was slow to sit up, his muscle tone was poor and at 1 year a diagnosis of cerebral palsy was made. In May, 1953, a ganglionic swelling was removed from his left foot which contained amorphous debris on histological examination. He was then showing signs of athetosis, for which physiotherapy was prescribed, and he was sent to a day school for children with cerebral palsy, which he still attends. In the same year he was admitted to hospital for investigation but developed pneumonia, after which the athetosis became more pronounced. In September, 1954, he developed diffuse painful swellings of the fingers and toes. Radiographs of the hands and feet revealed no abnormality and the sedimentation rate was $9 \mathrm{~mm}$./hr. (Westergren). A diagnosis of Still's disease was made and aspirin prescribed. In 1956 he suffered an exacerbation of his symptoms and in 1958, after a period of absence from school on account of pain and restlessness, he was seen with gross swellings of the fingers and toes. These were lilac in colour and studded with white calcareous deposits. The skin was ulcerated in several places and the appearances were those of gout. His blood uric acid at that time was $10.6 \mathrm{mg} . \%$ and he was treated with colchicine $-\frac{1}{2} \sigma$ gr. four times a day. Ten days later his restlessness was much improved and the lesions were less inflamed, but the dose had to be reduced to $\frac{1}{24} \mathrm{gr}$. on account of diarrhoea. This was later augmented with benemid. Shortly afterwards, as a result of infection entering through one of the ulcerated tophi, he developed a large abscess in his right forearm which however healed rapidly after incision but left him emaciated and anaemic. He was transfused on account of iron intolerance and the anaemia did not recur. While in hospital his lower lip became severely ulcerated and six teeth were extracted under general anaesthesia. This in turn led to bronchitis from which he recovered. After a seaside holiday he became much better nourished. On September 19, 1958, he developed a severe generalized convulsion from which he recovered rapidly.
At the present time he is a surprisingly contented child with a high grade mental defect. He can speak with difficulty and can assimilate simple teaching. He is very emaciated, weighing only $25 \mathrm{lb}$. at 7 years (Fig. 1) and he

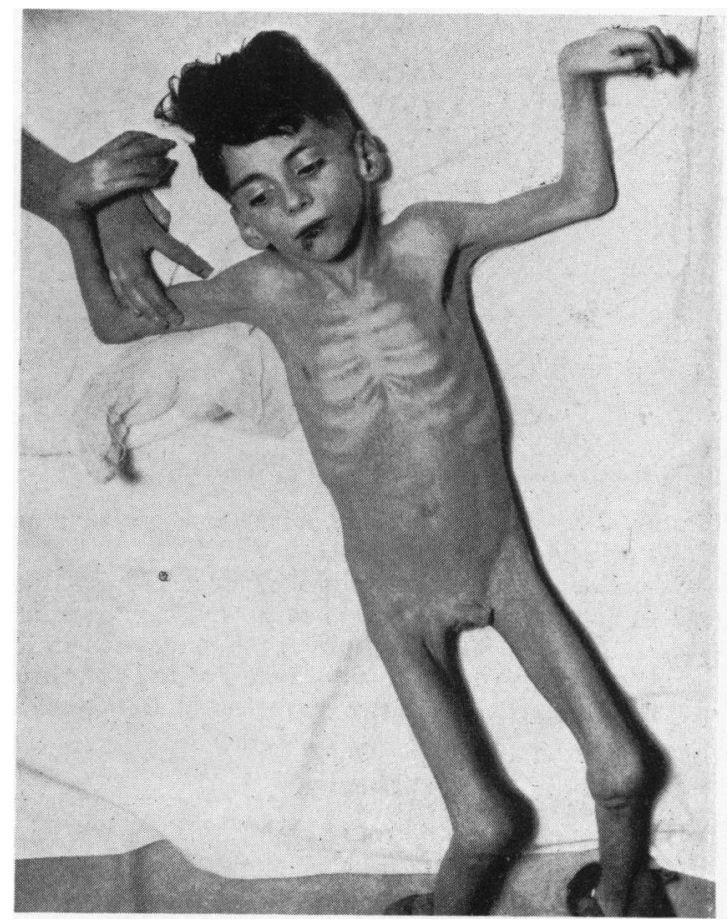

FIG. 1.-Showing emaciation and characteristic posture. Note bitten lip.

suffers from severe generalized athetosis with extensor spasms. He can neither sit nor stand unaided, grimacing is frequent, speech and swallowing are impaired and he salivates continually. The gout involves both hands and feet (Figs. 2 and 3 ) and the lobes of the ears. The digits are red and swollen with numerous white uratic deposits, and although partially controlled by treatment exacerbations are frequent. There has been no evidence of a 


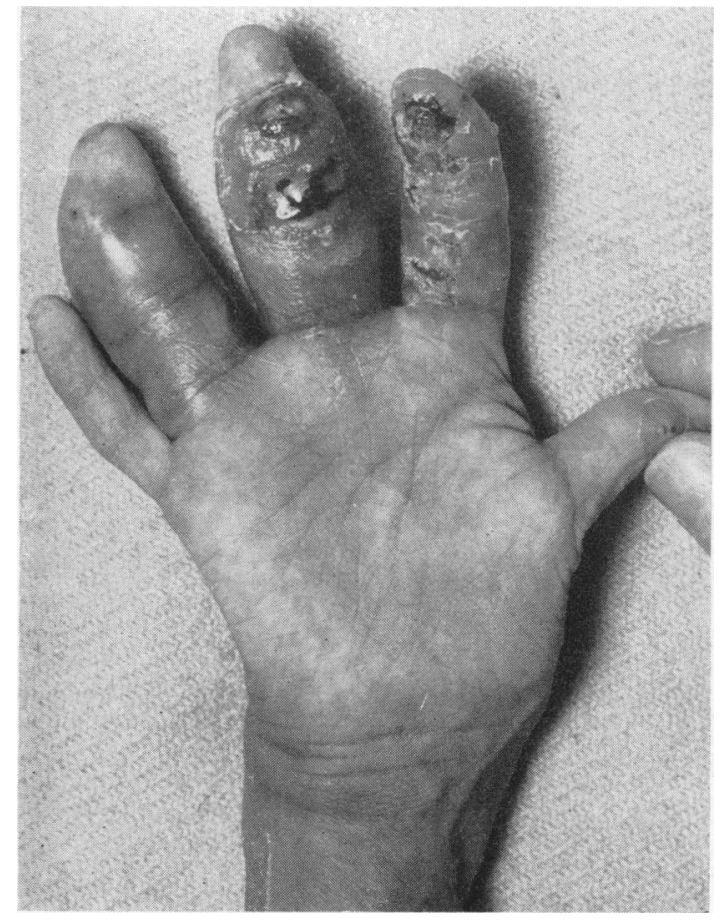

Fro. 2.-Ulcerated gouty lesions of hand.

return of his anaemia and bone marrow examination shows no evidence of leukaemia.

Other laboratory examinations include: 24-hour uric acid output $504 \mathrm{mg}$; blood urea $30 \mathrm{mg}$.\%; Mantoux reaction negative. Radiographs show gouty changes in the hands (Fig. 4) and also subluxation of the right hip. Chromatography of the urine shows no abnormality.

\section{Discussion}

Gout is very uncommon in childhood. Bernstein (1947), in an excellent historical review, says that Hippocrates, Sydenham and Heberden never saw it and that Hippocrates believes that it did not occur before puberty.

Sydenham, who developed gout at 25 , would certainly have remarked on it had he seen it. The first writer to describe it was Morgagni: 'Ipsi puellas vidi qui infanta vix peracta, acerbis articulorum doloris, prehensi decumbant'. The next writer is Gairdner (1854), who says that he had seen an infant on the breast who had a strong family history of gout. Still (1927) and Garrod (1876) also make reference to juvenile cases.

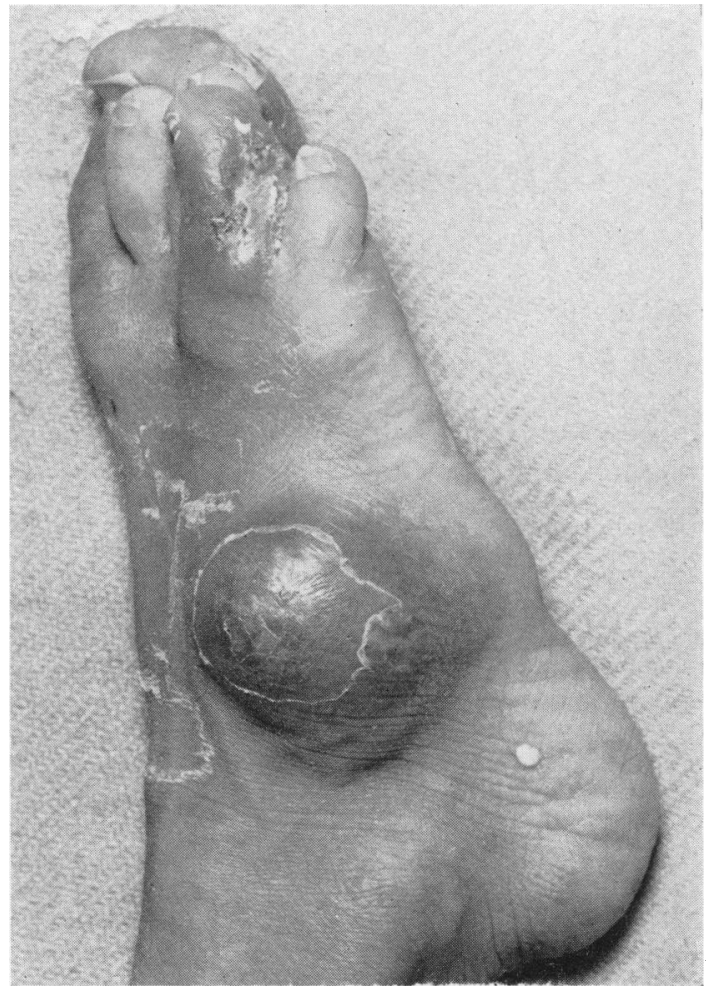

Fig. 3.-Gout and tophi on foot. Also inflamed ganglion.

In modern writings two types of juvenile gout are recognized, a rare, often fulminating type identical with that seen in adults, and a more common form associated with leukaemia or haemolytic anaemia. A further type associated with chronic liver disease has also been described. The first detailed description in a child is that of Mayer von Schopf (1930) in a baby of 5 weeks. This appears to have been of the adult type although it was associated with an anaemia. Death resulted from broncho-pneumonia. Two cases are recorded at $3 \frac{1}{2}$ years, one by Vining and Thompson (1934) in a child with leukaemia, and another by Rauch (1950) with symptoms from 3 years. Apart from these cases all the others were observed after the age of 10 . The maximum incidence of gout is in the fifth decade, and it declines in frequency in youth and age. Examples of gout in young persons are described by Claiborne (1940) at 17 years, Bernstein (1947) at 12, 14 and two at 16, Berk (1948) at 11 and Flinchum and Powers (1951) at 15, 26 and 25. Gout and leukaemia in a boy of 11 is recorded by Franck (1944), and anaemia and gout are recorded by 


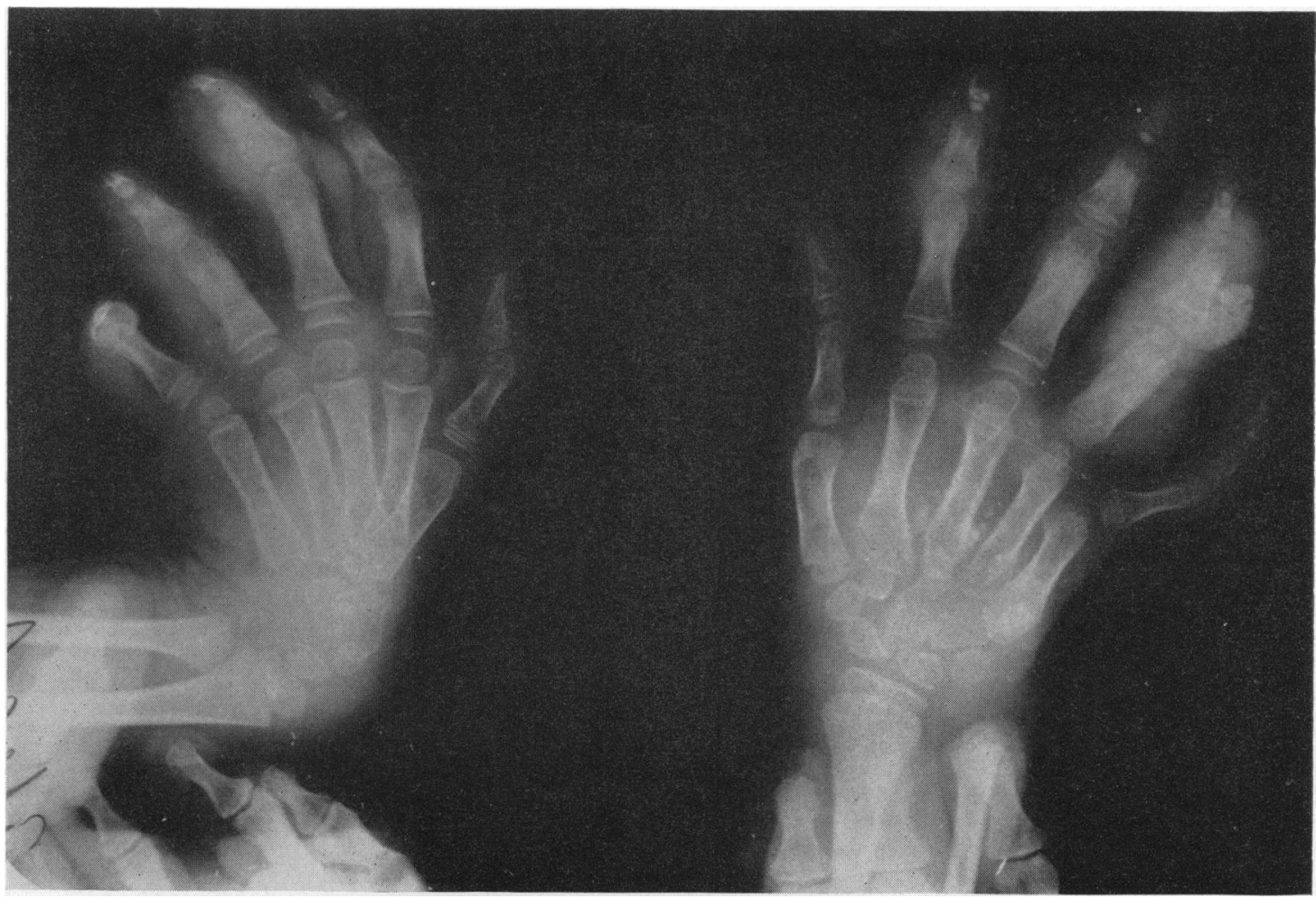

FIG. 4.-Radiograph of hands showing erosions and calcareous deposits.

Nordmann and Höhne (1951) in a child of 12; Morgano and Zino (1953) and Lambie (1940) also report cases. Jeune, Charrat and Bertrand (1957) describe two interesting cases of chronic liver disease associated with a high blood uric acid, one of whom suffered from gout.

No connexion between gout and disease of the central nervous system has been described apart from the degenerative vascular changes which it produces and one case of tophi in the spinal cord causing paraplegia (Koskoff, Morris and Lubic, 1953).

In the present case we believe that the poor general condition of the patient, which resulted from his cerebral palsy, may have aggravated an inherited gouty diathesis and resulted in the premature appearance of symptoms.

\section{Summary}

Gout is described in a boy with athetoid cerebral palsy. The disease was first observed at the age of 3 years. No connexion between the two conditions could be established.

The boy remains under the care of Mr. Kenneth Guest, F.R.C.S., and I am much indebted to him for referring him to me and allowing me to publish this report about him.

REFERENCES

erk, M. E. (1948). Gout-report of an unusual case in a young man. Amer. J. med. Sci., 215, 290.

Bernstein, S. S. (1947). Gout in early life. J. Mt Sinai Hosp., $14,747$.

Claiborne, T. S. (1940). Gout in a 17 year old girl. J. Amer. med. Ass., $115,38$.

Flinchum, D. and Powers, J. A. (1951). Gout in young people. N.C. med. J., 12, 433.

Franck, G. (1944). Leukose og Arthritis urica. Nord. Med., 21, 605.

Gairdner, W. (1854). On Gout, its History, its Causes, and its Cure, 3rd ed. Churchill, London.

Garrod, A. B. (1876). Gout and Rheumatic Gout, 3rd ed. Longmans, Green and Co., London.

Hippocrates, Aphorisms 6 , No. 30 .

Jeune, M., Charrat, A. and Bertrand, J. (1957). Polycorie hepatique -hyperuricémie et goutte. Arch. franç. Pédiat., 14, 897.

Koskoff, Y. D., Morris, L.E. and Lubic, L. G. (1953). Paraplegia as a complication of gout. J. Amer. med. Ass., 152, 37.

Lambie, C. G. (1940). A study of juvenile gout in a patient suffering from chronic erythronoclastic anaemia of obscure origin, together with observations upon the physical state of uric acid in the blood and the effects of splenectomy. Med. J. Aust., 1,535 .

Mayer von Schopf, E. (1930). Gicht bei einem 5 wochen alten Säugling. Klin. Wschr., 9, 2148.

Morgano, G. and Zino, F. (1953). Considerazioni su di un caso di gotta giovanile. Arch. E. Maragliano Pat. Clin., 8, 915.

Nordmann, M. and Höhne, K. H. (1951). Die juvenile Poikilocyten -Anämie mit generalisierter Arthritis urica. Folia haemat. (Lpz.), 71, 98.

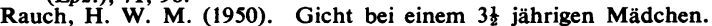
Med. Mschr., 4, 931 .

Still, G. F. (1927). Common Disorders and Diseases of Childhood. 5th ed. Oxford University Press, London.

Vining, C. W. and Thomson, J. G. (1934). Gout and aleukaemic leukaemia in a boy aged five. Arch. Dis. Childh., 9, 277. 